\title{
Growth of infants with neonatal growth hormone deficiency
}

\author{
$\mathrm{J} M$ Wit, $\mathrm{H}$ van Unen
}

\begin{abstract}
In view of contradictory reports on the growth hormone dependency of early postnatal growth we studied the growth curves of 15 infants with neonatal growth hormone deficiency. In seven infants the growth curve was parallel to the standards of the infancy-childhoodpuberty (ICP) model (group 1), but in the remaining infants there was an immediate deviation of the growth curve (group 2). In this group the mean (SD) at 4 and 9 months of age was $-3.3(1 \cdot 1)$ and $-4.9(1.4)$, respectively, when compared with the ICP model. The mean birth length in both groups was decreased and five out of 15 had a birth length of less than -2 SD. Serial measurements of the growth hormone response to provocation tests in two patients in group 2 showed decreasing concentrations, while four patients with documented complete growth hormone deficiency belonged to group 2 . We conclude that growth hormone is needed for early infant growth and that the normal growth pattern in some infants with neonatal pituitary dysfunction is due to incomplete insufficiency.
\end{abstract}

Neonatal or congenital growth hormone deficiency has been described as a rare form of growth hormone deficiency: in two series $1.8 \%$ and $5 \%$ of growth hormone deficient patients had clinical signs shortly after birth. ${ }^{12}$ The clinical presentation includes hypoglycaemia, prolonged jaundice, microgenitalia in boys, and failure to thrive. The majority of cases have multiple pituitary hormone deficiencies, particularly adrenocorticotrophic hormone (ACTH) and thyroid stimulating hormone (TSH) defi- ciencies, as a consequence of either hypothalamic or pituitary disease. ${ }^{23}$

There are few data on the growth pattern of infants with neonatal growth hormone deficiency. In most studies the data on length are scarce, but the observation that some children with documented growth hormone deficiency grow well in the first year of $\operatorname{life}^{24}$ has led several authors to state that growth in the first six months of life may be growth hormone independent. ${ }^{56}$ This concept has been used to provide a biological basis for the so called infancy-childhood-puberty (ICP) growth model which breaks down normal linear growth mathematically into three additive and partly superimposed components. The infant component is believed to be independent of growth hormone. ${ }^{45}$ However, when the available case reports are scrutinised it appears that some infants were already short in length after one month or just a few months, ${ }^{1278}$ and in a series of 14 infants $50 \%$ are reported as having immediate growth retardation. ${ }^{9}$

In order to clarify this apparent discrepancy we decided to study the growth pattern from birth to three years of age in all growth hormone deficient patients who presented shortly after birth with varying combinations of hypoglycaemia, prolonged jaundice, and micropenis.

\section{Patients and methods}

All patients with neonatal pituitary deficiency including growth hormone deficiency who presented to our clinic over the previous 10 years were included, provided that sufficient growth data were available over the first nine months of life. We chose to include only those
Department of Paediatrics, Division of Endocrinology, Wilhelmina Children's Hospital,

State University,

PO Box 18009,

3501 CA Utrecht,

The Netherlands

J Wit

H van Unen

Correspondence to:

Dr Wit.

Accepted 15 October 1991
Table 1 Clinical data. Plus or minus signs indicate the presence or absence of a condition or deficiency

\begin{tabular}{|c|c|c|c|c|c|c|c|c|c|c|c|}
\hline \multirow{2}{*}{$\begin{array}{l}\text { Case } \\
\text { No }\end{array}$} & \multirow[t]{2}{*}{ Sex } & \multirow{2}{*}{$\begin{array}{l}\text { Gestation } \\
\text { (weeks) }\end{array}$} & \multirow[t]{2}{*}{ Presentation } & \multirow[t]{2}{*}{ Asphyxia } & \multirow[t]{2}{*}{ Hypoglvcaemia } & \multirow[t]{2}{*}{ Micropenis } & \multirow[t]{2}{*}{ Faundice } & \multirow{2}{*}{$\begin{array}{l}\text { Growth hormone } \\
\text { peak in Mg/l } \\
\text { (age in momths) }\end{array}$} & \multicolumn{3}{|c|}{ Additional deficiencies } \\
\hline & & & & & & & & & $\overline{T S H}$ & $A C T H$ & Prolactin \\
\hline \multirow{2}{*}{$\begin{array}{c}\text { Group } \\
1\end{array}$} & & & & & & & & & & & \\
\hline & $\mathbf{M}$ & 32 & Breech & - & + & + & + & $\begin{aligned} 18 & (1) \\
5 & (3)\end{aligned}$ & + & + & - \\
\hline 2 & $\mathbf{M}$ & 36 & Breech & - & + & + & + & $\begin{aligned} 10 & (2) \\
3 & (13)\end{aligned}$ & + & + & - \\
\hline 3 & $\mathbf{M}$ & 36 & Head & - & + & - & + & $1(66)$ & + & + & - \\
\hline 4 & $\mathrm{~F}$ & 35 & Breech & - & + & & + & $1.5(108)$ & + & + & - \\
\hline 5 & $\mathrm{~F}$ & 40 & Transverse & - & + & & + & 2.5 (13) & + & + & - \\
\hline 6 & $M$ & 36 & Breech & + & + & + & + & 4.5 (12) & + & - & - \\
\hline 7 & M & 39 & Head & + & + & + & + & $6 \cdot 5(33)$ & + & + & - \\
\hline \multicolumn{12}{|c|}{ Group 2} \\
\hline 8 & M & 40 & Head & - & + & + & + & $+(2)$ & + & + & - \\
\hline 9 & $\ddot{M}$ & 40 & Head & - & $?$ & + & + & $<0^{\prime} 5(84)$ & + & - & + \\
\hline 10 & $\mathrm{~F}$ & 36 & Head & - & ? & & + & $4.5(16)$ & + & + & - \\
\hline 11 & $\mathrm{~F}$ & 40 & Breech & - & + & & + & $1(0.5)$ & + & + & - \\
\hline 12 & $\mathbf{F}$ & 37 & Head & - & + & & t & $2(21)$ & + & - & - \\
\hline 13 & $\mathrm{~F}$ & 42 & Head & - & + & & - & $6(12)$ & + & + & - \\
\hline 14 & $M$ & 40 & Head & - & + & + & - & $<0.5(120)$ & + & - & + \\
\hline 15 & $\mathbf{F}$ & 42 & Head & - & + & & + & $1(0 \cdot 5)$ & + & + & - \\
\hline
\end{tabular}


patients with clinical signs (micropenis, hypoglycaemia, and prolonged jaundice) documenting the existence of pituitary dysfunction in utero or at least immediately after birth. Clinical details are shown in table 1.

On the basis of the presenting clinical signs, the pituitary function was evaluated. Thyroid function was assessed by measuring serum total thyroxine and free thyroxine and by the TSH response to thyrotrophin releasing hormone (TRH) in a dosage of $0.2 \mathrm{mg} / \mathrm{m}^{2}$ body surface given as an intravenous bolus.

Adrenal function was assessed by measuring cortisol in at least three serum samples over 24 hours and by a short ACTH test (intravenous Synacthen $0.25 \mathrm{mg}$, Ciba Geigy). Serum prolactin was measured before and after the TRH bolus. All patients had multiple pituitary deficiencies (table 1). Two patients had an associated
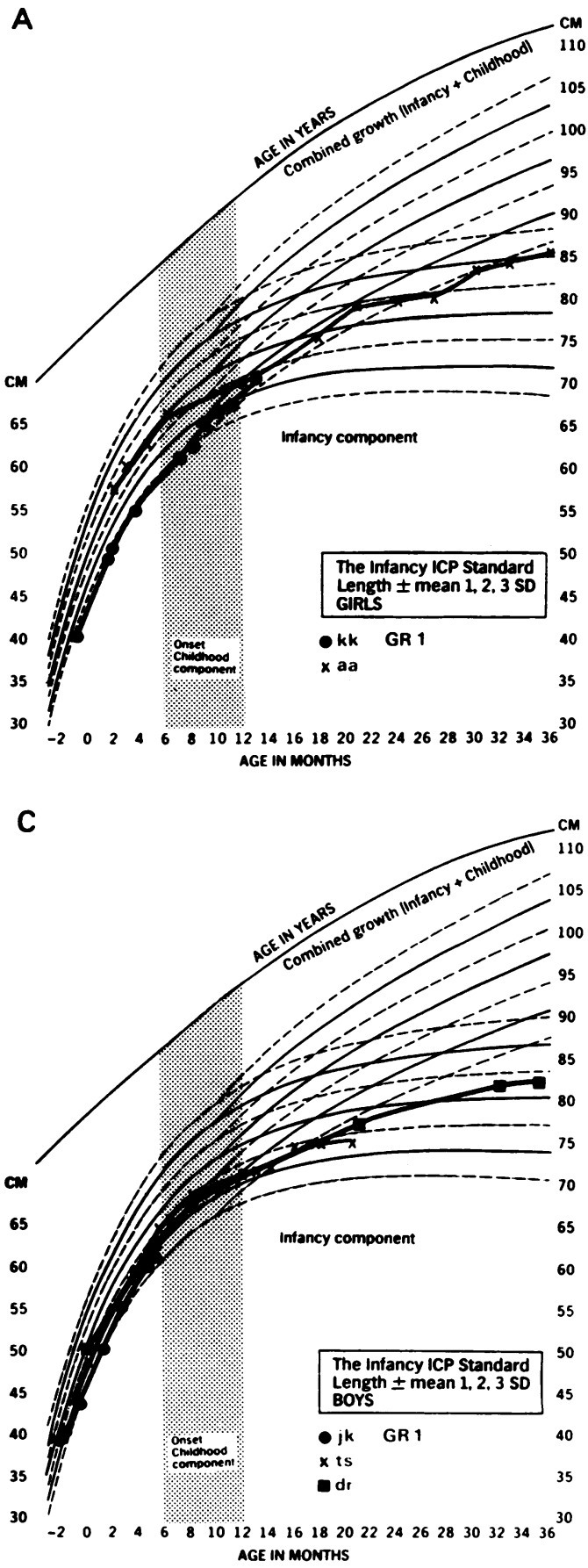

prolactin deficiency and TSH deficiency, which later proved to be a new hereditary syndrome. ${ }^{10}$ Adequate hormone replacement with hydrocortisone and thyroxine was given, as soon as the diagnosis was made. The age at diagnosis was below 8 weeks of age in nine out of 15 cases. In the two groups that were formed on the basis of the growth response (see results section) four out of seven cases in group 1 and in five out of eight cases in group 2 were diagnosed before 8 weeks. Growth hormone was tested by one or two standard provocation tests if the growth velocity decreased, but in two cases had already been tested at an earlier stage. In most instances an arginine infusion test was performed using $0.5 \mathrm{~g} / \mathrm{kg}$ body weight. A second test consisted either of a clonidine test $\left(0.15 \mathrm{mg} / \mathrm{m}^{2}\right.$ body surface, given by mouth) or a sleep test (blood sampling each 20 minutes over three hours).

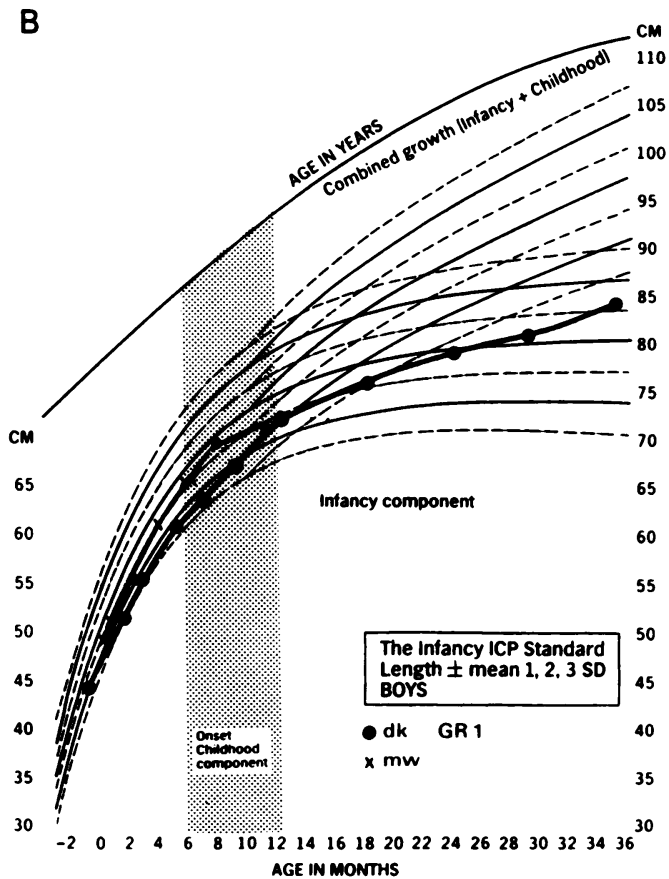

Figure 1 (A), (B), and (C) Individual growth curves of group 1 on the ICP standards. Copyright 1987, $\mathcal{F}$ Karlberg, ISBN 91-7900-265-X and copyright US 1989, $\mathcal{F}$ Karlberg TX 2560 182; published with permission. 
Individual growth curves were plotted on the ICP standard charts based on the Swedish longitudinal growth study ${ }^{5}$ until growth hormone treatment was started. We analysed length at 0,4 , and 9 months of age. In three patients treatment was started before the age of 9 months (cases 1, 8, and 15) and in case 14 only a length at 9 months was available. Lengths at 4 and 9 months were, if necessary, estimated by interpolation.

\section{Results}

Mean birth length was diminished (table 2) and five out of 15 infants had a birth length less than 2 SD below the mean for gestational age. ${ }^{11} \mathrm{~A}$ qualitative analysis of the growth curves showed that there were two distinct growth patterns. The first pattern was in concordance with the

A

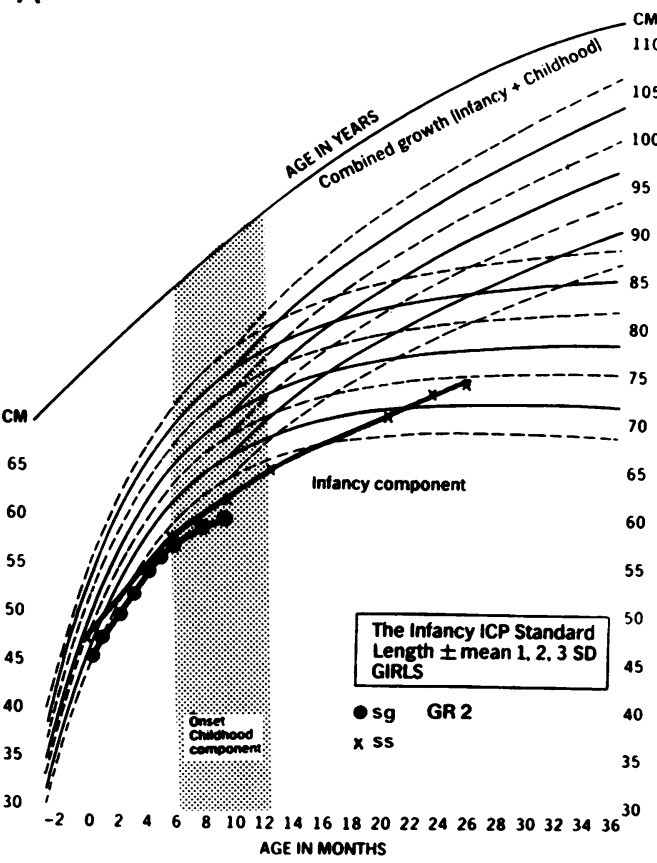

C

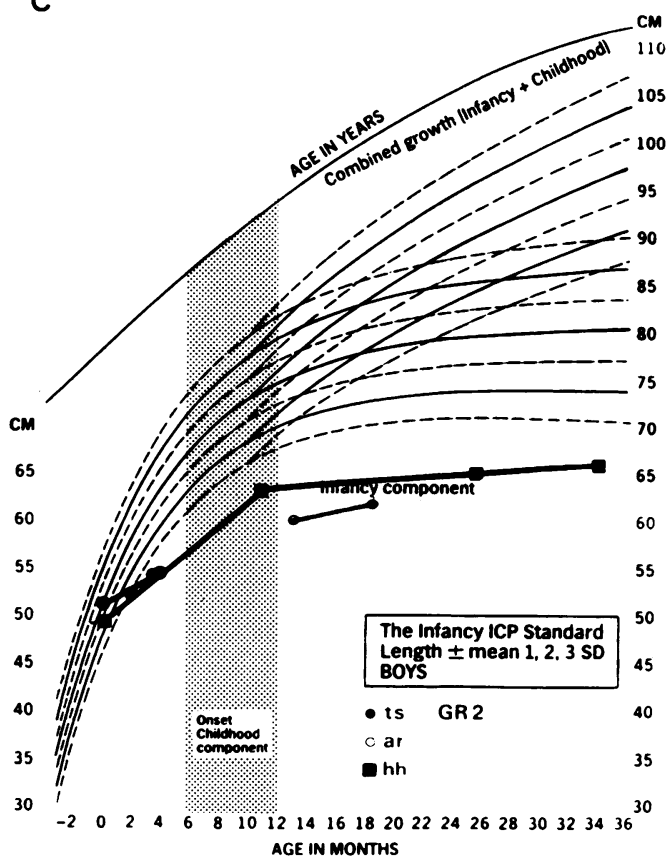

hypothesis that the infant component might be growth hormone independent, as the curves were parallel to the centiles up to 9 months followed by a gradual deviation (group $1, n=7$ ). The second pattern showed a downward deviation of the growth curve from birth onwards (group 2, $\mathrm{n}=8$ ). Individual curves are shown in figs 1 and 2 and the mean (SD) lengths at 0,4 ,

Table 2 Length SD score at 0, 4, and 9 months. Values shown as mean $(S D)$ compared with normal

\begin{tabular}{llllll}
\hline & Group 1 & & & Group 2 \\
\cline { 2 - 3 } \cline { 5 - 6 } & Length & No & Length & No \\
\hline 0 months & $-1.7(1.6)$ & 7 & & $-1.3(1.4)$ & 7 \\
4 months & $-1.5(1.2)$ & 7 & & $-3.3(1.1)$ & 7 \\
9 months & $-1.8(0.5)$ & $6 *$ & $-4.9(1.4)$ & $6 \dagger$ \\
\hline
\end{tabular}

* One patient excluded because of growth hormone treatment. †Two patients excluded (growth hormone treatment); in one patient length was only available at 9 months.

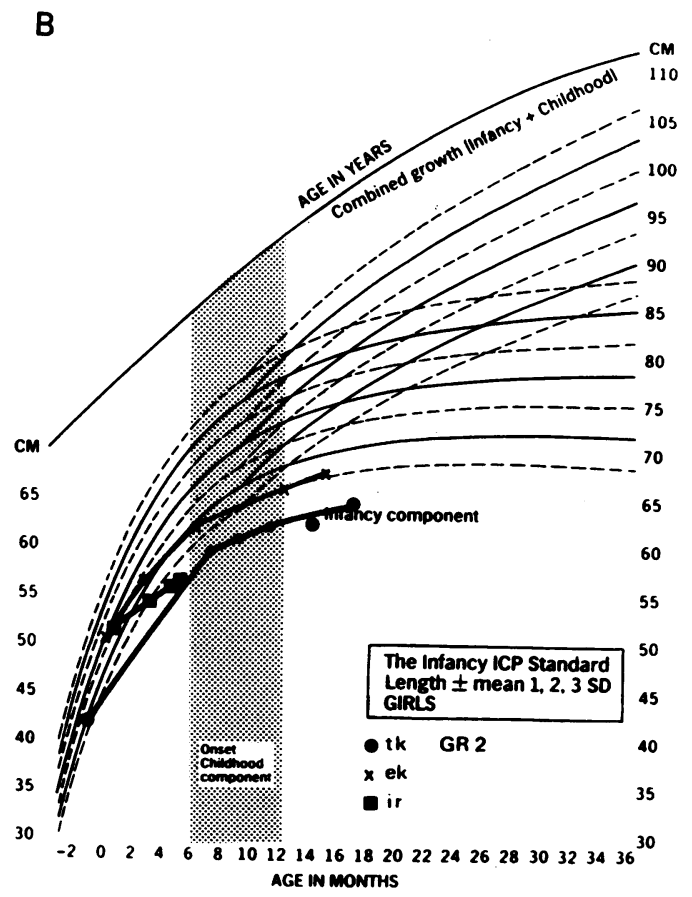

Figure $2(A),(B)$, and $(C)$ Individual growth curves of group 2 on the ICP standards. Copyright 1987, $\mathcal{F}$ Karlberg, ISBN 91-7900-265-X and copyright US 1989, $\mathcal{F}$ Karlberg TX 2560 182; published with permission. 
and 9 months of age (corrected for gestational age) are shown in table 2 .

Both groups were similar in the occurrence of associated deficiencies and of presenting signs (table 1), but five out of seven infants in group 1 were born in breech or transverse position compared with one out of eight in group 2 . With two exceptions, all patients had deficiencies of hypothalamic origin shown by an increased and delayed TSH response to TRH. The two patients with a total pituitary growth hormone deficiency had also a total prolactin deficiency and partial TSH deficiency. ${ }^{10}$ These patients and two patients with a total growth hormone deficiency of hypothalamic origin detected at 2 weeks of age all belonged to group 2 (length SD score at 9 months between $-7 \cdot 2$ and $-5 \cdot 3)$.

In two infants in group 1 , two consecutive arginine tests were performed at 1-2 months and at 3-13 months showing a decreasing growth hormone peak over time ( 18 to $5 \mu \mathrm{g} / 1,10$ to $3 \mu \mathrm{g} / \mathrm{l})$.

\section{Discussion}

Growth hormone is crucial for a normal statural growth during childhood, given a normal thyroid hormone secretion, but the exact age when it begins to regulate growth is uncertain. Based on few cases it has been suggested that growth hormone begins to exert a significant influence on linear growth towards the end of the first year of life. ${ }^{4-6}$ We have shown that approximately $50 \%$ of the infants with multiple pituitary deficiencies including growth hormone deficiency indeed grow normally in the first nine months of life, which is in line with the expectations on the basis of the ICP model. However, the growth curve of the remaining infants deviated sharply from the age-references immediately after birth. In a French study of 14 infants a similar percentage was observed. ${ }^{9}$ It is unlikely that this effect can be accounted for by the additional ACTH and TSH deficiencies, as hypocorticism and hypothyroidism were treated immediately after their appearance with appropriate dosages.

Our data are compatible with the hypothesis that some infants with neonatal panhypopituitarism do not have a complete growth hormone deficiency at birth, but develop such deficiency in the ensuing months. Of the infants who initially grew normally, two showed normal growth hormone peaks after provocation tests shortly after birth but these peaks decreased later. A similar phenomenon was observed in one out of 14 infants with neonatal growth hormone deficiency in the French study. ${ }^{9}$ The four patients who were certainly completely growth hormone deficient at birth showed an immediate growth retardation, providing evidence that growth hormone is necessary for early postnatal growth. This observation is in line with the findings of Tanner. ${ }^{12} 13$ While the ICP model appears to be a useful mathematical model to describe postnatal growth, the infancy and childhood components should not be associated with a growth hormone independent and growth hormone dependent growth phase, respectively.
If growth hormone is necessary for early postnatal growth, the question arises whether it might play some part in prenatal growth. So far, most authors concur that it is not necessary for prenatal growth and that insulin and insulinlike growth factors promote prenatal growth. ${ }^{14}$ In contrast, we have shown that five out of 15 infants had a birth length of less than -2 SD and the mean birth length was -1.7 and -1.3 in the two groups. However, when all reported cases were studied, there was no infant with a birth length of less than -2 SD out of the 10 birth length measurements reported, ${ }^{2} 8$ 15-19 although a birth weight of less than $2500 \mathrm{~g}$ was encountered in five out 34 neonates. Recently, the study of a large database revealed that the number of infants with a short birth length was higher than statistically expected. ${ }^{20}$ On the basis of these data it is uncertain whether growth hormone plays a part in prenatal growth and it seems more likely that the low mean birth length is caused by the additional pituitary deficiencies or by other factors not directly related to the pituitary deficiencies. All five infants with a short birth length had additional TSH and ACTH deficiencies, but this combination was also seen in the majority of the infants with normal birth lengths.

In agreement with previous studies, ${ }^{12}$ we have shown that hypoglycaemia, prolonged jaundice, and micropenis are important clinical clues to the presence of hypothalamic pituitary dysfunction in the neonate. Treatment with hydrocortisone $\left(6-12 \mathrm{mg} / \mathrm{m}^{2} /\right.$ day $)$ was in most cases sufficient to prevent further attacks of hypoglycaemia if the parents were instructed appropriately about increasing the dosage during stress. The micropenis could be treated successfully with three intramuscular injections of $25 \mathrm{mg}$ testosterone esters (Sustanon, Organon).

In conclusion, this study shows that growth hormone exerts a significant influence on linear growth from birth onwards and possibly even from before birth, in contrast to earlier reports and to the assumptions made in the ICP model.

1 Herber SM, Milner RDG. Growth hormone deficiency presenting under age 2 years. Arch Dis Child 1984;59. $557-60$.

2 Lovinger RD, Kaplan SL, Grumbach NM. Congenita hypopituitarism associated with neonatal hypoglycemia and microphallus: four cases secondary to hypothalamic hormone deficiencies. $\mathcal{F}$ Pediatr 1975;87:1171-81.

3 Reid JD. Congenital absence of the pituitary and adrenal cortex. F Pediatr 1956;48:633-9.

4 Karlberg J, Albertsson-Wikland K. Infancy growth pattern related to growth hormone deficiency. Acta Paediatr Scand 1988;77:385-91.

5 Karlberg J. On the modelling of human growth. Stat Med 1987;6:185-92.

6 Hindmarsh PC, Brook CGD. Normal growth and its endocrine control. In: Brook CGD, ed. Clinical paediatric endocrinology. Oxford: Blackwell Scientific Publications, 1989:

7 Ceelie N, Steendijk R. Aangeboren functiestoornissen van de hypothalamus berustend op een ontwikkelings-stoornis van het procencephalon. Tijdschr Kindergeneeskd 1981;49. 266-73.

8 Drop SLS, Colle E, Guyda HJ. Hyperbilirubinaemia and idiopathic hypopituitarisme in the newborn period. Acto Paediatr Scand 1979;68:277-80.

9 Gendrel D, Chaussain JL, Job JC. Les hypopituitarisme congénitaux par anomalie et la ligne médiane. Arch Fr Pediatr 1981;38:227-32.

10 Wit JM, Drayer NM, Jansen $M$, et al. Total deficiency of growth hormone and prolactin, and partial deficiency of 
thyroid stimulating hormone in two Dutch families: a new variant of hereditary pituitary deficiency. Horm Res 1989; 32:170-7.

11 Usher R, McLean F. Intrauterine growth of live-born caucasian infants at sea level: standards obtained from
measurements in seven dimensions of infants born between 25 and 44 weeks of gestation. 7 Pediatr 1969;74:901-10.

12 Tanner JM. Foetus into man. Physical growth from conception to Tanner JM. Foetus into man. Physical grow

13 Tanner JM. Principles of growth standards. Acta Paediatr Tanner JM. Principles
Scand 1990;79:963-5.

14 Milner RDG, Hill DJ. Interaction between endocrine and paracrine peptides in prenatal growth control. Eurf Pediatr 1987;146:113-22.

15 Kauchansky A, Genel M, Smith GJW. Congenital hypopituitarism in female infants. Am $\mathcal{Y}$ Dis Child 1979;133: $165-9$.
16 Copeland KC, Franks RC, Ramamurthy R. Neonatal hyperbilirubinemia and hypoglycaemia in congenital hypopituitarism. Clin Pediatr (Phila) 1981;20:523-6.

17 Lanes R, Blanchette V, Edwin C, et al. Congenital hypopituitarism and conjugated hyperbilirubinemia in two pituitarism and conjugated hyperbilin.

18 Cacciari E, Cicognani A, Pirazzoli P, et al. Congenital hypopituitarism associated with neonatal hypoglycemia and pituitarism associated with neonatal hypoglycemia and
microphallus: effect of $\mathrm{GH}$ therapy. Helv Paediatr Acta microphallus:

19 Herman SP, Baggenstoss AH, Cloutier MD. Liver dysfunction and histologic abnormalities in neonatal hypopituitarism. I Pediatr 1975;87:892-5.

20 Albertsson-Wikland K, Niklasson A, Karlberg P. Birth data for patients who later develop growth hormone deficiency: preliminary analysis of a national register. Acta Paediatr Scand 1990;370 Suppl:115-20.

Pain relief

What does a baby think when he (she) experiences pain? Does a baby experience pain or does he react to it in a reflex fashion? Does pain make a baby unhappy? Does the psychological repertoire of the newborn include happiness and unhappiness? How many angels can pirouette on a pin head?

I have referred briefly in the past (Archivist 1991: 1032) to the need for adequate analgesia for babies, quoting the work of Anand and Aynsley-Green. There seems no doubt that in the past we have all failed the babies under our care in this respect, perhaps being unduly influenced by concern about possible adverse effects of analgesia and perhaps by unanswerable philosophical speculations.

If there was any doubt remaining about the necessity for adequate analgesia for small babies it should be dispelled by another report from Dr Anand, this time with Dr P R Hickey, on work done in Boston, Massachusetts (New England fournal of Medicine 1992;326:1-9). In a prospective, randomised trial they measured hormonal and metabolic responses to cardiac surgery in 45 newborn babies, comparing two different methods of anaesthesia and analgesia. Fifteen babies received 'light anaesthesia and analgesia' with halothene, ketamine, pancuronium, and intravenous morphine during the operation and repeated morphine and diazepam postoperatively. The other 30 were given 'deep opiate anaesthesia and analgesia' using a continuous infusion of fentanyl or sufentanil and pancuronium as required. In response to surgery the babies given sufentanil produced less insulin and more adrenaline, noradrenaline, $\beta$ endorphin, glucagon, corticosteroids, and aldosterone than those given halothane and morphine. Blood glucose, lactate, and acetoacetate concentrations rose to higher values in the halothane group. The chemical measurements, therefore, gave evidence of an increased stress response in the 'light anaesthesia' group. The sufentanil group also did better in terms of clinical outcome. There were no postoperative deaths in this group $(n=30)$ but four in the halothane group $(n=15)$. After the study mortality from open heart surgery in the Boston Children's Hospital was reduced by more than $60 \%$. Morbidity too was significantly less in the sufentanil group in which postoperative sepsis, necrotising enterocolitis, disseminated intravascular coagulation, and metabolic acidosis did not occur whereas each of these complications occurred in $20 \%$ or more of babies in the halothane group.

So adequate anaesthesia and analgesia for babies is.not only humane in that it prevents pain, it also reduces mortality and morbidity. Babies are people and people need adequate pain relief. 